\title{
Leptospirosis: pulmonary hemorrhage in a returned traveller
}

\author{
Victor Leung MD, Me-Linh Luong MD, Michael Libman MD
}

A previously healthy 33 -year-old man experienced fever and general malaise seven days after returning from northeastern Malaysia. He had trekked in the jungle, swam in fresh water, consumed iodine-purified water and sustained many mosquito and leech bites during his three-week vacation. He had received all relevant vaccinations before travel and had adhered to atovaquone-proguanil chemoprophylaxis for malaria.

Two days after the onset of symptoms, he had visited a travel clinic. His physical examination, laboratory investigations and chest radiography had all been normal. A malaria smear and blood cultures had been negative. Results of all laboratory investigations are summarized in Table 1, and serial chest radiographs are shown in Figure 1. A follow-up visit had been arranged, and the patient had been sent home.

Five days after the onset of fever, he developed a dry cough and shortness of breath. At this time, he presented to our hospital's emergency department. On initial examination, he was febrile $\left(39.9^{\circ} \mathrm{C}\right)$ with a blood pressure of $91 / 58 \mathrm{~mm} \mathrm{Hg}$, a heart rate of 80 beats/min, a respiratory rate of 16 breaths/min and an oxygen saturation of $98 \%$ on room air. He was alert and oriented. His conjunctivae were normal and he did not appear jaundiced. His heart and breath sounds were also normal. Palpation of the calf muscles did not elicit any pain. Faint pink, blanchable, macular lesions were noted over his chest, abdomen and back. There were no signs of meningeal inflammation. The remainder of his physical examination was unremarkable. Laboratory investigations showed anemia, thrombocytopenia, acute renal failure and elevated aspartate aminotransferase (Table 1).

Chest radiography showed patchy airspace opacities involving both lung fields (Figure 1B). The patient was presumptively diagnosed with dengue fever and admitted for monitoring. A sputum Gram stain showed > 25 epithelial cells, suggesting oropharyngeal contamination. A nasopharyngeal swab subjected to reverse transcriptase real-time polymerase chain reaction yielded a negative result for influenza. He was not prescribed empiric antibiotics on admission.

Within 24 hours after admission, the patient experienced progressive respiratory distress, with worsening cough and recurrent episodes of hemoptysis (each yielding about $10 \mathrm{~mL}$ of blood). Because of hypoxemia, the patient was transferred to the intensive care unit, where he received noninvasive positive-pressure ventilation for 24 hours. $\mathrm{He}$ did not require intubation and received no transfusions. Laboratory investigations showed worsening anemia and liver transaminase but an improvement in platelets and kidney function.

Based on the patient's clinical presentation and a history that included exposure to fresh water while in Malaysia, we suspected leptospirosis infection and started empiric antibiotic therapy with ceftriaxone ( $1 \mathrm{~g} /$ day intravenously). His clinical condition improved dramatically within 48 hours and therapy was switched to oral administration of doxycycline (100 mg twice daily) for eight days. He was discharged five days after starting treatment and was doing well with no apparent sequelae at a three-month follow-up.

Leptospirosis infection was confirmed retrospectively by acute and convalescent serological testing performed at the National Microbiology Laboratory (Winnipeg, Man.). An enzymelinked immunosorbent assay (PanBio, Brisbane, Australia) of serum collected on day six of the patient's illness produced a positive result for Leptospira IgM. Microscopic agglutination assays against a panel of Leptospira serovars revealed an increase in titres against L. kirschneri serovar Grippotyphosa from 1:200

\section{KEY POINTS}

- Diseases associated with high mortality or substantial public health consequences must be ruled out when approaching a case of fever in the returned traveller.

- Leptospirosis should be included in the differential diagnosis of fever and pulmonary hemorrhage when there are epidemiologic risk factors (e.g., exposure to fresh water or floods, urban exposure to standing water where rodents may be present, ecotourism in swampy regions and working in agricultural areas or sewer systems).

- Suspected severe leptospirosis should be treated with penicillin or ceftriaxone before a diagnosis is serogically confirmed. 
to 1:1600 over a two-week interval. This serovar has previously been linked to outbreaks resulting from exposure to contaminated fresh water. ${ }^{1}$

\section{Discussion}

One approach to diagnosing fever in the returned traveller is to rule out treatable life-threatening illnesses, such as malaria and typhoid, and diseases with substantial public health consequences, such as hemorrhagic fevers and (given the recent pandemic) influenza A (see Box 1). Influenza was ruled out and bacterial pneumonia was unlikely in our patient, given the results of radiologic and microbiological investigations. A detailed history may therefore offer further clues toward a diagnosis in such scenarios. Useful information may include the dates and locations of all travel, both rural and urban, types of accommodation used, consumption of water or unpasteurized milk, diet, sexual history, contact with animals, insect bites, tattoos or piercings and participation in outdoor activities that may have involved exposure to fresh water.

\section{Fresh water and transmission}

Leptospirosis is an emerging infectious disease caused by several species and serovars of the spirochete Leptospira. The burden of disease is difficult to assess because reliable epidemiologic data are lacking; leptospirosis is not a reportable disease in many countries. The International Leptospirosis Society, in collaboration with the World Health Organization, attempted to collect worldwide incidence data in the year 2000. Unfortunately, only $12 \%$ of surveys were returned. The incidence (per 100000 people) ranged from 0.003 in Japan to 50 in the Andaman region of India. ${ }^{2}$

Table 1: Summary of laboratory investigations performed at the travel clinic and in hospital

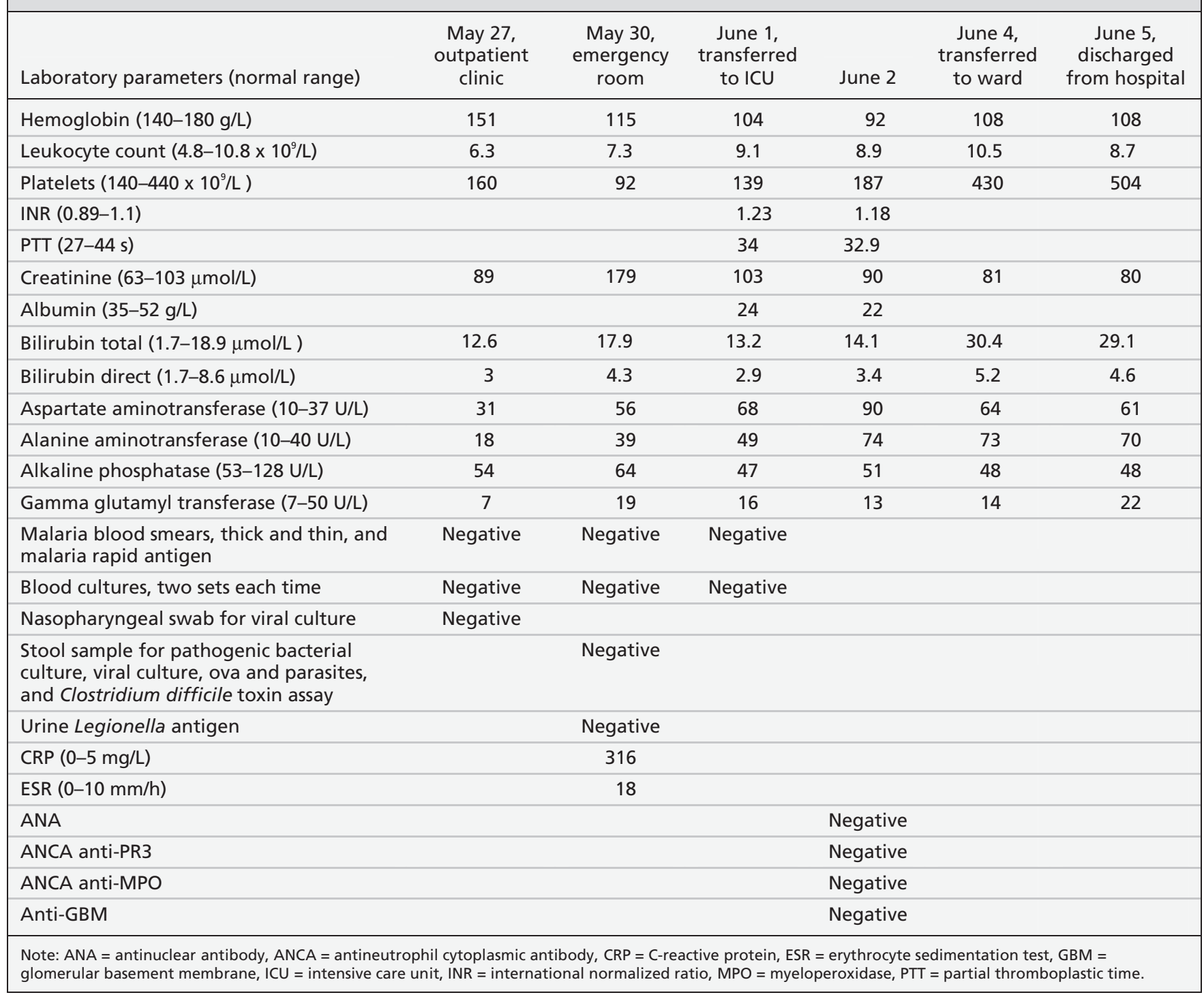


Rodents, thought to be the main source of transmission to humans, are infected during infancy and intermittently shed the organism in their urine. ${ }^{3}$ Humans are usually infected via skin abrasions or through the mucous membranes of the eyes, nose and mouth after exposure to fresh water contaminated with urine from infected animals. Sporadic outbreaks in humans have been linked to such exposures.

Leptospirosis has emerged as a disease in adventure travellers, especially among those who participate in water sports. ${ }^{4}$ People at higher risk of acquiring the disease include those in specific occupations (e.g., farmers, ranchers, sewer workers, rice field workers and laboratory personnel) and those exposed to certain household conditions (e.g., rodent infestation, pet dogs). ${ }^{1} \mathrm{We}$ hypothesize that our patient acquired leptospirosis while swimming in contaminated fresh water. His skin barrier was likely compromised by the multiple mosquito and leech bites he had previously sustained.
Box 1: Useful Internet resources for diagnosing infections in returning travellers

- Gideon (Global Infectious Diseases and Epidemiology Network):

www.gideononline.com

- World Health Organization, Global Alert and Response:

www.who.int/csr/resources/databases/en /index.html

- Public Health Agency of Canada, Committee to Advise on Tropical Medicine and Travel:

www.phac-aspc.gc.ca/tmp-pmv/catmat -ccmtmv/index-eng.php)

- Centre for Disease Control, Traveller's Health:

wwwnc.cdc.gov/travel/default.aspx

Information on recent outbreaks

- ProMED:

www.promedmail.org

- Healthnet:

www.healthnet.org

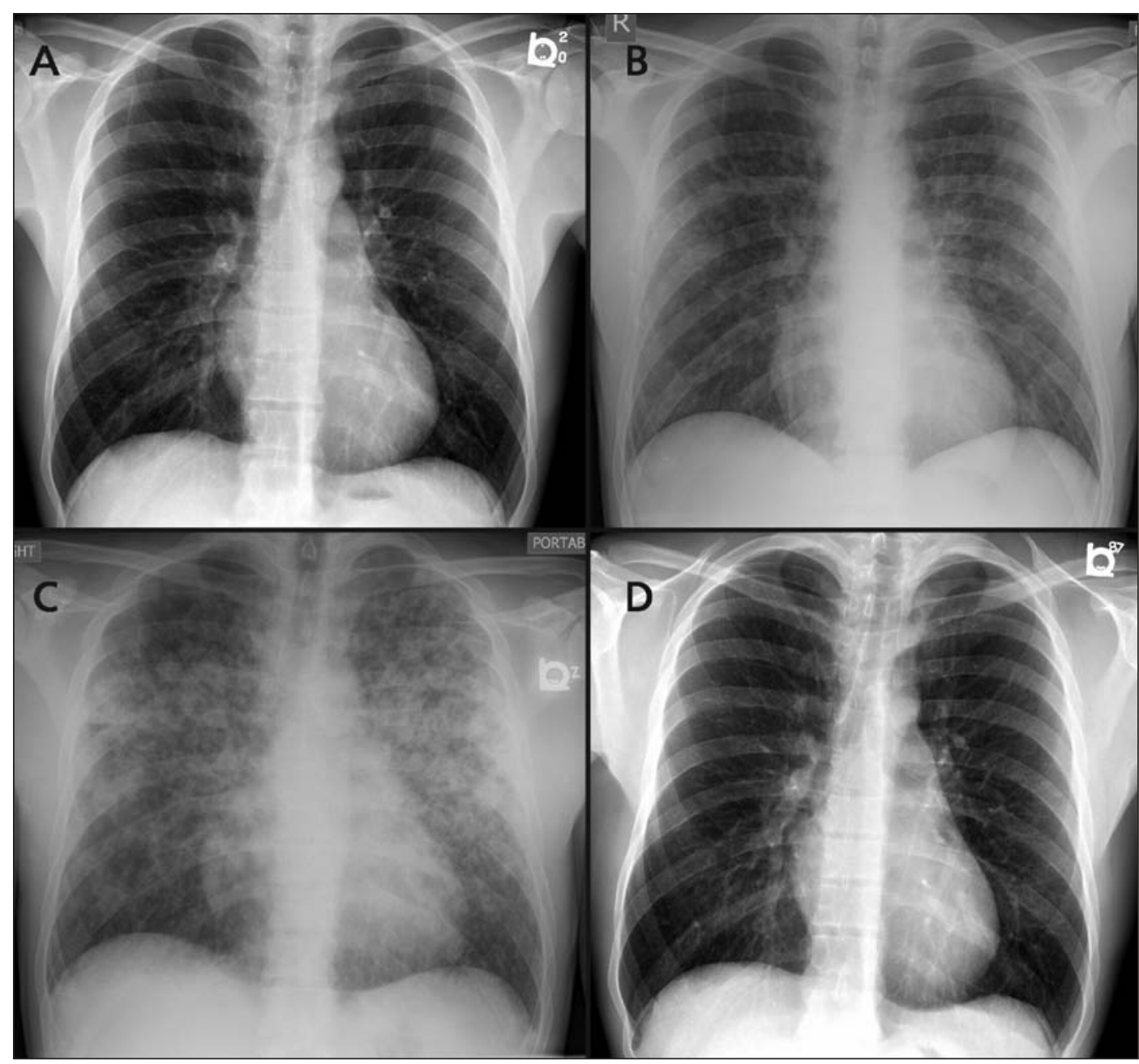

Figure 1: Serial chest radiographs of a 33-year-old man who presented with fever and hemoptysis, showing (A) a normal image on day four of illness, (B) patchy airspace opacities involving both lung fields on day seven, (C) worsening diffuse airspace opacification on day eight and (D) a normal image at three-months follow-up. 


\section{Wide spectrum of presentations}

The spectrum of disease (after an incubation period of 2-20 days) ranges from subclinical illness to severe and potentially fatal multiorgan failure. ${ }^{1}$ The broad range of manifestations and atypical presentations of leptospirosis can make it a challenging diagnosis. A differential diagnosis of infections presenting with fever and hemoptysis is listed in Table 2. Most infections are subclinical or manifest as a mild, undifferentiated, febrile illness classified as anicteric leptospirosis. These patients may present with sudden onset of fever, myalgia (particu-

\begin{tabular}{|c|c|c|}
\hline Cause & Diagnostic considerations & Methods of investigation \\
\hline \multicolumn{3}{|l|}{ Common } \\
\hline Bacterial bronchitis & $\begin{array}{l}\text { Productive cough with leukocytosis and } \\
\text { normal chest radiograph }\end{array}$ & Sputum culture \\
\hline Necrotizing bacterial pneumonia & $\begin{array}{l}\text { Rigors, pleuritic pain, lobar infiltrate and } \\
\text { leukocytosis }\end{array}$ & $\begin{array}{l}\text { Sputum culture } \\
\text { If Legionella is considered, obtain urine } \\
\text { Legionella antigen and notify laboratory for } \\
\text { special cultures }\end{array}$ \\
\hline Lung abscess & $\begin{array}{l}\text { Risk for aspiration; lobar infiltrate } \\
\text { with air-fluid level }\end{array}$ & $\begin{array}{l}\text { Sputum culture } \\
\text { Consider fine needle aspiration }\end{array}$ \\
\hline Pulmonary tuberculosis & $\begin{array}{l}\text { Cough, night sweats, weight loss, } \\
\text { prolonged fever }\end{array}$ & $\begin{array}{l}\text { Sputum for AFB stain and mycobacteria culture } \\
\text { Place patient on airborne isolation }\end{array}$ \\
\hline Mycetoma (fungus ball) & Chronic cavitary lung disease & $\begin{array}{l}\text { Sputum fungal culture } \\
\text { Histopathology of biopsy material }\end{array}$ \\
\hline Invasive pulmonary aspergillosis & Immunocompromised host & $\begin{array}{l}\text { Sputum fungal culture } \\
\text { Serum and BAL galactomannan } \\
\text { Radiologic imaging } \\
\text { Histopathology of biopsy material }\end{array}$ \\
\hline \multicolumn{3}{|l|}{ Uncommon } \\
\hline Plague (Yersinia pestis) & $\begin{array}{l}\text { Severe prostration and severe pneumonia; } \\
\text { extreme, painful swelling of lymph nodes } \\
\text { (bubos); contact with rodents or wildlife } \\
\text { mammals }\end{array}$ & $\begin{array}{l}\text { Sputum gram stain (gram negative bipolar } \\
\text { Coccobacilli) } \\
\text { Sputum culture } \\
\text { Blood culture } \\
\text { Place patient on droplets isolation }\end{array}$ \\
\hline $\begin{array}{l}\text { Endemic mycosis (histoplasmosis, } \\
\text { blastomycosis, coccidiomycosis) }\end{array}$ & Travel to endemic area & Sputum fungal culture \\
\hline Amoebic lung abscess & Travel to endemic area & $\begin{array}{l}\text { Needle aspiration and direct examination of } \\
\text { aspirate } \\
\text { Serology }\end{array}$ \\
\hline Hydatid lung cyst & $\begin{array}{l}\text { Travel to endemic area, contact with dog or } \\
\text { sheep }\end{array}$ & $\begin{array}{l}\text { Radiologic imaging } \\
\text { Serology } \\
\text { Avoid diagnostic needle aspiration as this could } \\
\text { cause dissemination of disease }\end{array}$ \\
\hline Schistosomiasis & $\begin{array}{l}\text { Travel to endemic area } \\
\text { Contact with fresh water }\end{array}$ & $\begin{array}{l}\text { Stool for ova and parasite } \\
\text { Urine for ova } \\
\text { Serology }\end{array}$ \\
\hline Paragonimiasis & $\begin{array}{l}\text { Pulmonary infection with bloody and rust- } \\
\text { coloured sputum, possible CNS symptoms } \\
\text { and eosinophilia; ingestion of inadequately } \\
\text { cooked or pickled crustaceans }\end{array}$ & $\begin{array}{l}\text { Sputum and stool for ova } \\
\text { Serology }\end{array}$ \\
\hline Meliodosis & $\begin{array}{l}\text { Travel to endemic area (particularly during } \\
\text { rainy season), contact with fresh water }\end{array}$ & $\begin{array}{l}\text { Gram stain (bipolar gram negative bacilli) } \\
\text { Culture } \\
\text { Direct fluorescent antibody }\end{array}$ \\
\hline Leptospirosis & $\begin{array}{l}\text { Nephritis, hepatitis, myositis and } \\
\text { conjunctival suffusion; contact with fresh } \\
\text { water }\end{array}$ & $\begin{array}{l}\text { Serology (microscopic agglutination test) } \\
\text { Dark field microscopy of urine }\end{array}$ \\
\hline
\end{tabular}


larly in the calves), conjunctival suffusion, transient maculopapular rash and headache, as well as pulmonary and gastrointestinal symptoms. The mortality associated with anicteric leptospirosis is low, and patients usually make uneventful recoveries.

Icteric leptospirosis is a much more severe form of the disease, occurring in about $15 \%$ of infected patients. ${ }^{1}$ These patients may present with fulminant sepsis, severe jaundice, acute renal failure and pulmonary hemorrhage. The mortality rate associated with icteric leptospirosis is high. ${ }^{1}$ In a large prospective cohort of 173 patients with acute severe leptospirosis, the overall mortality rate was $5.8 \% ; 10.4 \%$ among patients requiring dialysis and $29 \%$ among patients with respiratory failure. ${ }^{5}$

Pulmonary involvement occurs in $20 \%-70 \%$ of patients. It usually manifests between the fourth and sixth day of illness and can present with mild nonproductive cough, dyspnea, hemoptysis and acute respiratory distress syndrome. ${ }^{6}$ Pulmonary hemorrhage is considered the major cause of death in leptospirosis infection, and represents one aspect of a systemic vasculitic syndrome that may develop with or without the other elements of icteric disease. ${ }^{6}$ In our patient, the acuity of the bilateral airspace disease and hemoptysis suggested pulmonary hemorrhage and alerted us to the possibility of leptospirosis.

\section{Usefulness of laboratory testing}

Given the typically nonspecific laboratory results, a high index of suspicion is required to make a diagnosis of leptospirosis. An early hint may be thrombocytopenia, which develops in up to $50 \%$ of patients and usually correlates with the occurrence of nonoligouric renal failure. ${ }^{7}$ The icteric form is more easily recognized, typically presenting with severe hepatic dysfunction (with bilirubin level disproportionately elevated compared with transaminase levels) and renal dysfunction. ${ }^{1}$ Peripheral leukocytosis with a left shift ${ }^{1}$ and elevated serum creatinine phosphokinase levels may occur in severe leptospirosis. ${ }^{8}$

The microscopic agglutination test is the reference standard for serologic diagnosis of leptospires. The criterion for a positive microscopic agglutination test is a four-fold increase in antibody titre or a conversion from seronegativity to a titre of $\geq 1: 100$. Microscopic agglutination test titres are reported as the reciprocal value of the number of dilutions still agglutinating $50 \%$ of live organisms. However, owing to the expertise required to perform the analysis and the high interlaboratory variation in microscopic agglutination test results, the use of commercially available assays that can detect IgM antibodies during the first week of illness is on the rise. ${ }^{9}$

\section{Controversy in treatment}

There is controversy regarding the best therapeutic management of leptospirosis. Evidence supporting the efficacy of antibiotics in the treatment of leptospirosis remains limited. ${ }^{10}$ However, cases that receive medical attention are typically more severe, and most experts would recommend initiating antibiotics. ${ }^{11}$

Many antibiotics are active against leptospirosis. ${ }^{12}$ The current treatment options for leptospirosis include doxycycline, penicillin and third-generation cephalosporins. Doxycycline is used to treat mild to moderate cases of the disease. ${ }^{3}$ Penicillin is considered the drug of choice for treating severe instances of the disease, but recent clinical trials have shown that thirdgeneration cephalosporins are just as effective. ${ }^{12}$ More recently, in vitro susceptibility studies have shown promising results with macrolides and cefepime; ${ }^{13}$ however, further clinical trials are needed to support the use of these agents in the treatment of leptospirosis.

\section{References}

1. Levett PN. Leptospirosis. Clin Microbiol Rev 2001;14:296-326.

2. Chesney MA, Chambers DB, Taylor JM, et al. Social support, distress, and well-being in older men living with HIV infection. J Acquir Immune Defic Syndr 2003;33(Suppl 2):S185-93.

3. Bharti AR, Nally JE, Ricaldi JN, et al. Leptospirosis: a zoonotic disease of global importance. Lancet Infect Dis 2003;3:757-71.

4. Morgan J, Bornstein SL, Karpati AM, et al. Outbreak of leptospirosis among triathlon participants and community residents in Springfield, Illinois, 1998. Clin Infect Dis 2002;34:1593-9.

5. Panaphut T, Domrongkitchaiporn S, Vibhagool A, et al. Ceftriaxone compared with sodium penacillin $\mathrm{G}$ for treatment of severe leptospirosis. Clin Infect Dis 2003;36:1507-13.

6. Dolhnikoff M, Mauad T, Bethlem EP, et al. Leptospiral pneumonias. Curr Opin Pulm Med 2007;13:230-5.

7. Edwards CN, Nicholson GD, Everard CO. Thrombocytopenia in leptospirosis. Am J Trop Med Hyg 1982;31:827-9.

8. Johnson WD Jr, Silva IC, Rocha H. Serum creatine phosphokinase in leptospirosis. JAMA 1975;233:981-2.

9. Bajani MD, Ashford DA, Bragg SL, et al. Evaluation of four commercially available rapid serologic tests for diagnosis of leptospirosis. J Clin Microbiol 2003;41:803-9.

10. Guidugli F, Castro AA, Atallah AN, et al. Antibiotics for treating leptospirosis [review]. Cochrane Database Syst Rev 2010;(1):CD001306

11. Vinetz JM. A mountain out of a molehill: Do we treat acute leptospirosis, and if so, with what? Clin Infect Dis 2003;36:1514-5.

12. Griffith ME, Hospenthal DR, Murray CK. Antimicrobial therapy of leptospirosis. Curr Opin Infect Dis 2006;19:533-7.

13. Ressner RA, Griffith ME, Beckius ML, et al. Antimicrobial susceptibilities of geographically diverse clinical human isolates of Leptospira. Antimicrob Agents Chemother 2008;52:2750-4.

14. Fartoukh M, Parrot A, Khalil A. Aetiology, diagnosis and management of infective causes of severe haemoptysis in intensive care units. Curr Opin Pulm Med 2008;14:195-202.

15. Principles and practice of infectious diseases. 7th ed. In Mandell GL, Bennett JE, Dolin R, editors. Philidelphia (PA): Churchill Livingstone Elsevier; 2010.

Affiliations: From the Division of Infectious Diseases, Departments of Medicine and Medical Microbiology, McGill University Health Center, Montréal, Que.

Contributors: Victor Leung and Me-Linh Luong drafted the manuscript. All of the authors critically revised the manuscript for important intellectual content and approved the final version submitted for publication. 